\title{
Lack of correlation between heterozygosity and fitness in forked fungus beetles
}

\author{
MICHAEL WHITLOCK \\ Department of Biology, Vanderbilt University, Nashville, TN 37235, U.S.A.
}

\begin{abstract}
Heterozygosity for loci coding for soluble proteins often is correlated with indicators of fitness such as body size, deviation from the population mean, or fluctuating asymmetry (FA). A large sample of over 900 forked fungus beetles (Bolitotherus cornutus) was measured for a series of morphological characters and genotyped using electrophoresis. No significant associations were found among heterozygosity and any of these fitness indicators at either the level of individual beetles or populations of beetles. There is no indication that individuals of extreme phenotypes have higher levels of FA. Furthermore there are weak correlations among the FA values of different characters, which is consistent with expectations of developmental instability but an unusual empirical result. Seemingly general patterns of heterozygosity and heterosis can be rejected in this species.
\end{abstract}

Keywords: body size, Bolitotherus cornutus, developmental stability, fluctuating asymmetry, heterozygosity, morphological variation.

\section{Introduction}

Heterosis, the fitness advantage enjoyed by outcrossed individuals, has been observed since the beginning of evolutionary biology and plays an undoubtedly large role in the evolutionary processes of most species (Charlesworth \& Charlesworth, 1987). Still, little is known for certain about the mechanisms of heterosis and its converse, inbreeding depression. Since the advent of electrophoresis and the direct observation of protein products of polymorphic structural genes, many attempts have been made to correlate heterozygosity with some characteristic associated with fitness, such as developmental stability (Palmer \& Strobeck, 1986), growth rate (Mitton \& Grant, 1984; Zouros \& Foltz, 1987), or morphological variance (Zink et al., 1985). Even though patterns of association between heterozygosity and fitness components have been demonstrated many times, insufficient data exist to determine the generality of the correlations between electrophoretic heterozygosity and fitness, due to the probability that negative results are under-reported (Booth et al., 1990).

Increases in morphological variance have often been seen to accompany decreases in heterozygosity. Since

Present address: Institute for Cell, Animal, and Population Biology, University of Edinburgh, Ashworth Laboratory, King's Buildings, Edinburgh EH9 3JT, Scotland. the work of Mitton (1978) on killifish and Eanes (1978) on monarch butterflies, many species have been reported to have a negative correlation between deviation from mean phenotypes and heterozygosity (Leamy, 1982; Fleisher et al., 1983). Other studies (Handford, 1980; McAndrew et al., 1982; Zink et al., 1985; Houle, 1989; Booth et al., 1990) have failed to find such a correlation despite, in some instances, fairly large sample sizes.

To measure the level of developmental stability of an individual or population, we may look not only at morphological variation among individuals, but also at variation within individuals. More precisely, for phenotypic characters which are ideally symmetric, we may examine variations from absolute symmetry. Fluctuating asymmetry (FA), or unsigned inequality between left and right analogous traits, has often been used as an elegant measure of developmental stability (van Valen, 1962), for two reasons. First, in each instance in which it has been measured, there is no heritability for direction of asymmetry (see Palmer \& Strobeck, 1986 for review). In other words, left and right characters in most cases are controlled by exactly the same genes. Furthermore, for most characters, particularly external characters which affect locomotion or motor control, it is straightforward to hypothesize that the optimal phenotype is symmetry, an "a priori knowledge of the ideal" (Palmer \& Strobeck, 1986). Developmental stability as measured by FA has been 
shown to be correlated with heterozygosity in several species: salmonid fishes (Leary et al., 1983, 1984, 1985), mice (Leamy, 1984); side-blotched lizards (Soulé, 1979), poeciliid fishes (Vrijenhoek \& Lerman, 1982; Quattro \& Vrijenheok, 1989), and bivalves (Kat, 1982), for example. One species of salmon has failed to demonstrate any correlation between FA and heterozygosity (Leary et al., 1984), but the sample sizes in this study are insufficient to allow sufficient power to prevent Type II errors. Recommendations to conservation biologists have been made from the perspective that not substantial negative results have been reported from studies in the wild (Parsons, 1990). The only study of sufficient statistical power that has failed to find this correlation is on Drosophila melanogaster (Houle, 1989).

Several other patterns have been predicted for asymmetry. Soule has theorized that in certain circumstances phenotypically more extreme individuals will exhibit greater FA, because of the greater homozygosity of extreme individuals (Soulé, 1982). Some ambiguous evidence for this hypothesis exists (Soule \& Couzin-Roudy, 1982). Furthermore, an interesting paradox appears in the literature (Palmer \& Strobeck, 1986). While in many species FA in several characters is correlated with heterozygosity, the FA of individual characters is not correlated with the FA of other characters on the same individuals, despite presumably high character correlations (Soulé \& Baker, 1968; Fox, 1975; Noss et al., 1983). This pattern is predicted if the number of loci contributing to symmetry is large (Palmer \& Strobeck, 1986).

Fitness is also often gauged by growth rate and compared with heterozygosity (see reviews by Mitton \& Grant, 1984 and Zouros \& Foltz, 1987). Positive correlations have been observed in body size or growth rate and heterozygosity for a variety of species from bivalves (Singh \& Zouros, 1978) to amphibians (Pierce \& Mitton, 1982; Whitehurst \& Pierce, 1991), from humans (Bottini et al. 1979) to pine trees (Mitton \& Grant, 1980). "The phenomenon appears to be general" (Mitton \& Grant, 1984, p. 487; but see Houle, 1989).

Taken together, the studies cited above would seem to demonstrate meaningful associations between allozyme diversity and some morphological and physiological traits correlated with fitness, with few exceptions. In this paper, a large morphological and allozyme data set on the forked fungus beetle, Bolitotherus cornutus, is presented which demonstrates that homozygosity is uncorrelated with several characters associated with fitness: body size, FA, aberrant morphology, and deviations from mean phenotypes. Furthermore, in this paper small but significant corre- lations among characters in asymmetry are demonstrated and the symmetry of bilateral characters in phenotypically extreme individuals is analysed. These data together demonstrate that not all species follow the seemingly general patterns, but that at least one species, Bolitotherus cornutus, is unusual in several regards.

\section{Methods}

Bolitotherus cornutus, the forked fungus beetle, lives in small populations on a patchy resource, the fruiting bodies of three polypore fungi. These beetles are relatively sedentary, moving rarely from one fallen log to another, creating a population structure with local inbreeding (Whitlock, 1992). These beetles were collected in Giles County, VA, near the Mountain Lake Biological Station in the summer of 1988, from 42 populations in a three hectare area on Salt Pond Mountain and 53 populations in a similar area on Butt Mountain. The collection techniques are described in more detail in Whitlock (1992). All collections were live frozen and stored at $-70^{\circ} \mathrm{C}$.

Horizontal starch gel electrophoresis was used to assess protein polymorphism. Nine of 21 loci were polymorphic: isocitric acid dehydrogenase-1 (IDH-1), isocitric acid dehydrogenase-2 (IDH-2), esterase (EST), hydroxybutyric acid dehydrogenase (HAD), glutamate-oxaloacetate transaminase (AAT), phosphoglucose isomerase (PGI), malic enzyme (ME), fumarase (FUM), and a dipeptidase (PEP). Five of these (IDH-1, EST, HAD, AAT, and PEP) were used for further analysis. The other loci were excluded because of very low frequencies of the rare alleles in Virginia and therefore gave insufficient statistical power for tests on heterozygosities.

Tissue grinding was done on ice in either distilled water or a 0.2 molar Tris $\mathrm{HCl}$ solution $(p \mathrm{H} 8)$, using the prothorax and head. Electrophoresis and staining procedures followed Werth (1985), except for HAD, which was done using cellulose acetate electrophoresis and substituted gluconic acid for $\beta$-hydroxybutyric acid (Hebert \& Beaton, 1989).

Homozygosity was calculated from five enzyme loci: IDH1, PEP, EST, GOT, and HAD (see Whitlock, 1992 for electrophoretic methodologies). In all analyses, the total number of loci at which an individual is homozygous was counted and that total used as its score. Population homozygosity was the average of these scores for all individuals in the population.

At the time of grinding for electrophoresis, the elytra, legs, and wings were placed in $1.5 \mathrm{ml}$ Eppendorf microcentrifuge tubes and frozen. The wings and legs were later mounted between two standard $75 \times 25 \times$ 
$1 \mathrm{~mm}$ glass microscopic slides (Clay Adams Gold Seal Micro Slides), bound by tape at each end (Borror et al., 1981). These slides were then projected using a protection microscope onto a Houston Instrument Hipad DT11 digitizer connected to an Apple II + microcomputer. Software was written to allow receipt and storage of the data from the digitizer. Elytra were subsequently measured using the projection microscopic and digitizer. Any damaged materials were not used. Bilaterally symmetrical characters were measured on both sides of the beetle and averaged; individual characters such as elytra width were doubly measured. All data were plotted against their replicates; any obvious mismatches were remeasured. The correlation of double measures was quite high $\left(r^{2}=0.99\right)$. The data were then transferred to the CTRVAX mainframe at Vanderbilt University for analysis by SAS (SAS Institute, 1985).

The characters used in the morphological analyses are as follows: second and third femur length $(2 \mathrm{~F}$ and $3 \mathrm{~F})$, second and third tibia length ( $2 \mathrm{~T}$ and $3 \mathrm{~T})$, elytral length (ELEN), elytral width (EWID), and 14 wing venation characters. The wing measures are mapped on Fig. 1 and designated by the letter $\mathrm{W}$ followed by the two numbers of the endpoints. For example, the distance between points 1 and 16 is called W1-16.

These morphological data were analysed using PROC PRINCOMP to generate principal component scores. PROC GLM and PROC NESTED were used to analyse the partitioning of variance of the first seven principal components (SAS Institute, 1985). Principle components were used rather than raw data for two reasons. First, principal component analysis allows simultaneous investigation of many different morpho- logical attributes which may be highly correlated and therefore uninterpretable en masse (Flury, 1988). The characters used in this analysis are indeed highly correlated. Secondly, using principal components may allow much of the noise of the distribution to be relegated to the unused minor components.

The bilateral data were reduced to two indices of fluctuating asymmetry. Each character for each individual was transformed to $\mathrm{FA}_{1}=|\mathrm{L}-\mathrm{R}| /((\mathrm{L}+\mathrm{R}) \mid$ 2) and also to $\mathrm{FA}_{2}=(\mathrm{L}-\mathrm{R})^{2}$, as recommended by Palmer \& Strobeck (1986). The first index corrects for character size variation; the second does not. The FA values were summed over all characters for each individual, to give an index for that individual. Population indices were computed as the average for all individuals in that population.

Several tests were applied to these data. The regression between FA and homozygosity was calculated for both individual and population levels. $\mathrm{FA}_{2}$ was used individually for each character regressed on the five locus homozygosity. Significant positive slopes are expected under the prediction of developmental heterosis. Furthermore, a simple single factor ANOVA compared the unscaled $\mathrm{FA}_{2}$ of each character for heterozygotes vs. homozygotes at each locus.

To determine the importance of heterozygosity to body size and morphological variability, principal components (PC) were computed (PROC PRINCOMP, SAS Institute, 1985). The wing characters, elytral length, and elytral width were used in this analysis. (The omitted characters had high frequencies of missing data; a single missing data point would exclude an individual from principal component analysis.) The first principal component had positive contri-

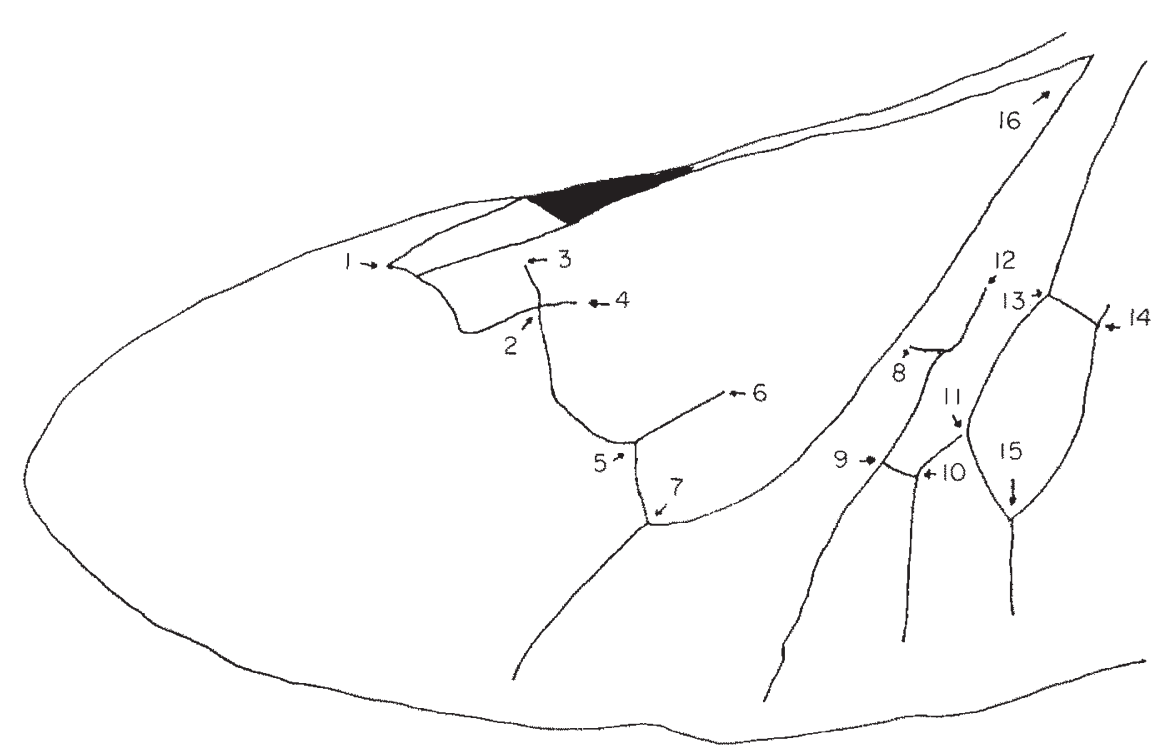

Fig. 1 The wing landmarks. Eighteen of the distances between these landmarks were used in this study. The abbreviation W1-16 refers to the distance between landmarks 1 and 16 . The eighteen distances used were W116, W8-16, W1-2, W2-3, W2-4, W2-5, W5-6, W5-7, W5-8, W7-8, W8-9, W1011, W8-12, W11-13, W13-14, W1415, W7-16 and W9-12. 
butions from each character with approximately equal weightings; this first PC was used as an index of body size. Total homozygosity and homozygosity at each locus were regressed on the first PC; to test for population level patterns, the means of each population were calculated and regressed. The regression of the first PC on homozygosity would have a negative slope with heterosis for growth rate and body size.

The linear distance from the multivariate mean of the first seven principal components was used as an indication of the morphological deviation. Regression of this deviation on homozygosity was performed at both the level of the individual and of the populationmean, using total homozygosity and homozygosity at each locus separately. The slope of this relationship should be positive under the heterosis hypothesis.

To test Soulés hypothesis of increased variance among phenotypically extreme individuals, a regression of the $\mathrm{FA}_{1}$ index was performed on the deviation from the multivariate PC mean.

Finally to test for correlations of FA across characters within individuals, a correlation matrix was generated using PROC CORR (SAS Institute, 1985) of $\mathrm{FA}_{1}$. A combined probability test was performed to pool information across character combinations (Sokal \& Rohlf, 1981). Only those characters which did not share an end-point were used in the correlation analysis.

\section{Results}

Over 900 beetles were collected and analysed. Individual tests sometimes had fewer because of damage during the mounting process. The eigenvalues of the first seven principal components are shown in Table 1.

Individual homozygosities regressed on either index of FA have no significant slope, contrary to the alternative hypothesis of heterosis. Only one of 115 comparisons is significant at the $P=0.05$ level, which is less than the expected Type I error rate. Moreover, the $r^{2}$ values are extremely low (range 0.00000-0.01278,

Table 1 Proportion of variance explained by the first seven morphological principal components

\begin{tabular}{lcll}
\hline & Eigenvalue & Proportion & Cumulative \\
\hline PRIN1 & 13.25 & 0.6309 & 0.6309 \\
PRIN2 & 1.31 & 0.0624 & 0.6933 \\
PRIN3 & 1.05 & 0.0501 & 0.7434 \\
PRIN4 & 0.98 & 0.0466 & 0.7900 \\
PRIN5 & 0.74 & 0.0352 & 0.8252 \\
PRIN6 & 0.64 & 0.0306 & 0.8558 \\
PRIN7 & 0.61 & 0.0291 & 0.8849 \\
\hline
\end{tabular}

median 0.00044) Similarly, when homozygosity is averaged over loci, regressions of homozygosity and the unscaled $\mathrm{FA}_{2}$ index for each character are not significant (see Table 2). Only one character (W13-14) of 23 had a significant correlation at the $P=0.05$ level, again less than expected by Type I errors. Regressions of the scale-adjusted $\mathrm{FA}_{1}$ index on homozygosity summed over loci similarly show no association between developmental stability and genetic identity. Thus the negative result is robust to the method of analysis.

The power of the tests above is substantial, because of the large sample sizes. For example, in the last test given, comparing total FA to total homozygosity, an $r^{2}=0.005$ would be statistically significant at the $P=0.05$ level. An $r^{2}$ this low would be biologically meaningless; sufficient power exists in these tests to safely claim a very small probability of significant Type II error. Nor are there significant correlations between homozygosity and FA at the population level. A simple regression using 65 populations between the summed $\mathrm{FA}_{1}$ and total homozygosity at the five loci revealed no significant relationship $\left(\beta=-0.31, \quad r^{2}=0.0138\right.$, $P=0.1719$ ).

The regressions of body size (PC1) and total homozygosity were also not significant $(\beta=-0.136$,

Table 2 Relationship of five locus heterozygosity to fluctuating asymmetry: $r^{2}$ values for each morphological character

\begin{tabular}{lll}
\hline Character & $r^{2}$ & $P$ \\
\hline 2F & 0.0167 & 0.1453 \\
2T & 0.0054 & 0.2184 \\
3F & 0.0102 & 0.2302 \\
3T & 0.0053 & 0.1073 \\
W1-16 & 0.0004 & 0.5927 \\
W8-16 & 0.0012 & 0.7065 \\
W1-2 & 0.0002 & 0.9139 \\
W2-3 & 0.0016 & 0.5665 \\
W2-4 & 0.0000 & 0.8693 \\
W2-5 & 0.0092 & 0.0561 \\
W5-6 & 0.0014 & 0.4569 \\
W5-7 & 0.0033 & 0.1495 \\
W5-8 & 0.0009 & 0.6219 \\
W7-8 & 0.0012 & 0.5878 \\
W8-9 & 0.0022 & 0.3796 \\
W10-11 & 0.0022 & 0.2663 \\
W8-12 & 0.0002 & 0.7817 \\
W11-13 & 0.0014 & 0.8008 \\
W13-14 & 0.0061 & 0.0356 \\
W14-15 & 0.0011 & 0.7168 \\
W11-15 & 0.0045 & 0.8117 \\
W7-16 & 0.0000 & 0.9542 \\
W9-12 & 0.0001 & 0.9052 \\
\hline
\end{tabular}


adjusted $\left.r^{2}<0.0001, \quad P=0.3216\right)$. Furthermore, ANOVAs for each locus with homozygosity as a class variable revealed no significant difference in the size of heterozygotes and homozygotes. Table 3 shows the specific results of these analyses.

Similarly, at the population level no connection between homozygosity and average body size was observed $\left(\beta=-0.735, \quad r^{2}=0.0044, \quad P=0.2630\right)$. When loci are considered separately, only one test, that using EST homozygosity, was significant $(\beta=-2.99$, $r^{2}=0.0842, \quad P=0.012$ ), but amount of variation explained is small. The remaining loci display no significant relationship between homozygosity and size at the population level (see Table 4). Thus these beetles display no biologically significant correlation between body size and homozygosity, at any level at which tests are performed.

There was also no evidence for heterosis for deviation from multivariate means. No significant regression between the multivariate deviation and total homozygosity was found $(t=0.960 ; P=0.337)$. This pattern is confirmed by analyses done at the population level; the average deviation from the multivariate mean of a population is not correlated with group homozygosity $\left(\beta=0.0065\right.$, adjusted $\left.r^{2}=-0.0016, \quad P=0.3465\right)$. Table 5 catalogues the relationships between individual loci and average deviation. Only one regression is significant, with the enzyme HAD; again the amount of variance explained by the comparison is small. The other four loci fail to reflect any relation of homo-

Table 3 The relationship between heterozygosity at each locus and body size, as measured by the first principal component

\begin{tabular}{lll}
\hline Enzyme & $r^{2}$ & $p$ \\
\hline PEP & 0.000003 & 0.9650 \\
GOT & 0.000034 & 0.8771 \\
EST & 0.000659 & 0.4946 \\
HAD & 0.002473 & 0.1856 \\
IDH1 & 0.004292 & 0.0811 \\
\hline
\end{tabular}

Table 4 Population level regressions of the first principal component on heterozygosity at individual loci

\begin{tabular}{lrrr}
\hline Enzyme & $\beta$ & Adjusted $r^{2}$ & $P$ \\
\hline PEP & -1.456 & 0.0034 & 0.2757 \\
GOT & 1.739 & 0.0132 & 0.1811 \\
EST & -2.989 & 0.0842 & 0.0120 \\
HAD & -0.453 & -0.0151 & 0.7804 \\
IDH1 & 0.2953 & -0.0150 & 0.7729 \\
\hline
\end{tabular}

zygosity and morphological variance. Thus there is little evidence of any sort of positive association between electrophoretic protein heterozygosity and fitness in forked fungus beetles, for any of the parameters measured.

No significant correlation was expressed between the $\mathrm{FA}_{2}$ and morphological deviation, contrary to Soulé's extreme phenotype hypothesis. Only one (W5$6)$ of the 23 characters demonstrated any significant relationship of $\mathrm{FA}_{2}$ with distance from the multivariate mean (see Table 6); this is expected at the $P=0.05$ level by random error. Furthermore, the $\mathrm{FA}_{1}$ summed over all characters has no significant relationship with deviation $(N=709, t=1.168, P=0.2434)$.

Table 5 Population level regressions of deviation from multivariate mean on heterozygosity

\begin{tabular}{lccc}
\hline Enzyme & $\beta$ & Adjusted $r^{2}$ & $P$ \\
\hline PEP & -0.018 & 0.0122 & 0.1892 \\
GOT & 0.014 & 0.0002 & 0.3176 \\
EST & 0.003 & -0.015 & 0.7839 \\
HAD & 0.039 & 0.0717 & 0.0192 \\
IDH1 & 0.0000 & -0.0164 & 0.9993 \\
\hline
\end{tabular}

Table 6 Regressions of the fluctuating asymmetry of morphological characters on deviations from multivariate means

\begin{tabular}{|c|c|c|c|}
\hline Character & $\beta$ & Adjusted $r^{2}$ & $P$ \\
\hline $2 \mathrm{~F}$ & 0.0050 & -0.0060 & 0.7205 \\
\hline $2 \mathrm{~T}$ & 0.0146 & -0.0001 & 0.3221 \\
\hline $3 F$ & 0.0041 & -0.0066 & 0.8503 \\
\hline $3 \mathrm{~T}$ & 0.0066 & -0.0049 & 0.5996 \\
\hline W1-16 & 0.0209 & -0.0043 & 0.5407 \\
\hline W8-16 & 0.0134 & -0.0064 & 0.8089 \\
\hline W1-2 & 0.0002 & -0.0068 & 0.9634 \\
\hline W2-3 & 0.0111 & 0.0070 & 0.1550 \\
\hline W2-4 & 0.0134 & 0.0151 & 0.0731 \\
\hline W2-5 & 0.0009 & -0.0068 & 0.9706 \\
\hline W5-6 & -0.0227 & 0.0308 & 0.0185 \\
\hline W5-7 & -0.0014 & -0.0060 & 0.7314 \\
\hline W5-8 & 0.0061 & -0.0062 & 0.7672 \\
\hline W7-8 & 0.0071 & -0.0061 & 0.7497 \\
\hline W8-9 & -0.0031 & -0.0067 & 0.8896 \\
\hline W10-11 & -0.0009 & -0.0068 & 0.9284 \\
\hline W8-12 & 0.0099 & -0.0055 & 0.6581 \\
\hline W11-13 & -0.0098 & 0.0004 & 0.3063 \\
\hline W13-14 & -0.0011 & -0.0066 & 0.8522 \\
\hline W14-15 & 0.0237 & -0.0035 & 0.4894 \\
\hline W11-15 & 0.0387 & 0.0009 & 0.2885 \\
\hline W7-16 & 0.0646 & 0.0099 & 0.1177 \\
\hline W9-12 & 0.0214 & 0.0022 & 0.2515 \\
\hline
\end{tabular}


There is slight evidence that fluctuating asymmetry values can be correlated across characters, as would be expected if the characters themselves are genetically or environmentally correlated. Excluding measurements which share a common endpoint (e.g. W1-16 and W816 share point 16 ), six of 42 correlations are significant at the $P=0.02$ level, four at the $P=0.01$ level. A combined probability test over all 42 of these comparisons gives $\chi^{2}=127.92$ with 84 d.f. $(P<0.001)$. Only eleven of these 42 correlations are negative (significantly different from 50:50 G-test $\chi^{2}=9.92, P<0.005$ ). The average slope of the relationship is quite small, 0.029 in all 42 correlations and 0.130 in the significant correlations. In these beetles, therefore, there are some small but real correlations between the FA on one character and the FA at another.

\section{Discussion}

Clearly, soluble protein polymorphisms in forked fungus beetles have little correlation with several commonly measured fitness indicators. Developmental stability, as measured by both morphological variance and fluctuating asymmetry, is not related to measured heterozygosity at either the individual or population level. Body size, an important correlate of fitness in these beetles (Brown \& Bartalon, 1986; Conner, 1988, 1989) and many other species (Peters, 1983), is also not related to homozygosity. These results have several implications.

These data should be viewed in a broader context. Often negative results go unreported, which biases our perception of the importance of certain processes. Bolitotherus cornutus displays patterns contrary to many of those observed in other species on which reports have been made (see Table 4, Palmer \& Strobeck, 1986). This is the first report of the lack of correlation between homozygosity and fluctuating asymmetry at the population level in wild-caught organisms with sufficient power to eliminate Type II errors (see Houle, 1989). Thus a pattern which has been observed in several species is not general, at least with the five protein loci measured in this study.

Several facts may partially account for the negative results presented here. First, it is possible that no biologically significant heterosis occurs upon outbreeding in this population. These beetles undergo periodically recurrent, if weak, inbreeding (Whitlock, 1992), which may purge the population of some of the deleterious effects of inbreeding (Falconer, 1981; Charlesworth \& Charlesworth, 1987).

The lack of correlation at the individual level may reflect the fact that a few loci poorly predict total heterozygosity, in the absence of linkage and inbreed-

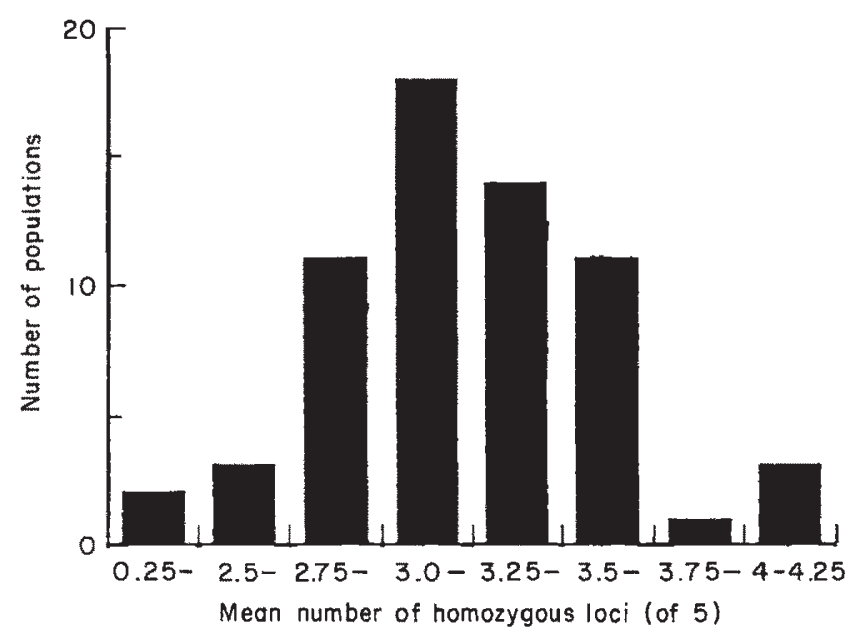

Fig. 2 The distribution of average heterozygosities across populations. The variance in this distribution predicts that different individual heterozygosities may represent different levels of inbreeding.

ing (Chakraborty, 1987), a problem general to most analyses of enzyme-associated heterozygosity. These beetles do, however, have some variance in the amount of inbreeding (Whitlock, 1992), which allows more predictive power (Chakraborty, 1987). In fact, the variance in mean heterozygosities of populations is quite high (see Fig. 2), and therefore the predictive power of the tests done at the population level should be high. This concordance of results for FA at the population level with those at the individual level is unusual (Palmer \& Strobeck, 1986).

The lack of relationship between homozygosity and FA indices observed in these beetles should serve as a cautionary tale against uncritical application of the recommendations of some to use $\mathrm{FA}$ in conservation biology as an index of biological 'stress', such as that caused by decreased heterozygosity (Quattro \& Vrijenhoek, 1989; Leary \& Allendorf, 1989; Parsons, 1990, 1992). While it seems reasonable in the context of the weight of data across species to interpret increases in FA as indicators of stress, this study indicates that the converse is not true; we may not infer a lack of such genetic stress in species which do not display increased FA.

Bolitotherus individuals display another unusual attribute: the fluctuating asymmetry for some characters is significantly correlated with that of other characters. The strength of these correlations is weak, and other studies which have asked similar questions suffered from smaller sample sizes, which indicates that this pattern may not be unusual but merely difficult to document. The lack in other species of correlations among characters on their asymmetry values is some- 
what surprising in the context of the almost certain environmental and genetic correlations among some of those characters (Falconer, 1981). Asymmetry values are supposed to be affected by environmental ('stress') and genetic ('homozygosity') factors (Leary \& Allendorf, 1989), so it is expected that characters on the same organism should experience similar degrees of instability. The data presented here confirm that such a pattern does in fact exist when sufficient sample sizes are considered in an appropriate way (i.e. an unsigned FA index). The fact remains that not much of the variance in FA is described by FA for other characters; more work is needed to resolve this apparent paradox.

The results presented here should also be interpreted carefully in the context of the dominancecorrelation hypothesis of Houle (1989). This hypothesis predicts that one should find heterosis in species whose population structures have gametic disequilibrium and inbreeding due to small population sizes. Bolitotherus clearly fits this category more than the species described by Houle, yet fails to display any heterosis. Therefore the patterns discussed by Houle relating heterosis to partial inbreeding are not completely general.

The relationship of heterozygosity and fitness in forked fungus beetles seems to be unusual in a number of ways. No heterosis for developmental stability, body size, or morphological constancy was observed. There is much left to be understood about heterosis in natural conditions; more studies are needed, and attention to negative as well as positive results will allow elucidation of possible patterns and processes.

\section{Acknowledgements}

This paper has benefited greatly from the kind review of D. McCauley, B. Pierce, P. Phillips, and anonymous reviewers. I thank Mt. Lake Biological Station for the use of their facilities for the collection and Vanderbilt University for research grants and computing time.

\section{References}

BOOTH, C. L., WOODRUFF, D. S. AND GOULD, S. J. 1990. Lack of significant associations between allozyme heterozygosity and phenotypic traits in the land snail Cerion. Evolution, 44, 210-213.

BORROR, D. J., DE LONG, D. M. AND TRIPLEHORN, C. A. 1981. An Introduction to the Study of Insects, Fifth Edition. Saunders, Philadelphia.

BOtTini, E., Gloria-BOtTinI, F., LUCARElli, P., POlZinetTl, A., SANTORO, F. AND VARVERI, A. 1979. Genetic polymorphisms and intrauterine development: Evidence of decreased heterozygosity in light for dates human newborn babies. Experientia, 35, 1565-1567.
BROWN, L. AND BARTALON, J. 1986. Behavioral correlates of male morphology in a horned beetle. Am. Nat., 127, 565-570.

CHAKRABORTY, R. 1987. Biochemical heterozygosity and phenotypic variability of polygenic traits. Heredity, 59, 19-28.

CHARLESWORTH, D. AND CHARLESWORTH, B. 1987. Inbreeding depression and its evolutionary consequences. Ann. Rev. Ecol. Syst., 18, 237-268.

CONNER, J. 1988. Field measurements of natural and sexual selection in the fungus beetle, Bolitotherus cornutus. Evolution, 42, 736-749.

CONNER, J. 1989. Density-dependent sexual selection in the fungus beetle, Bolitotherus cornutus. Evolution, 43, 1378-1386.

EANES, W. F. 1978. Morphological variance and enzyme heterozygosity in the monarch butterfly. Nature, 276, $263-264$.

FALCONER, D. S. 1981. Introduction to Quantitative Genetics. Longman Scientific and Technical, New York.

FLEISHER, R. C., JOHNSON, R. F. AND KLITZ, w. J. 1983. Allozymic heterozygosity and morphological variation in house sparrows. Nature, 304, 628-630.

FLURY, B. 1988. Common Principle Components and Related Multivariate Models. Wiley, New York.

FoX, S. F. 1975. Natural selection on morphological phenotypes of the lizard Uta stansburiana. Evolution, 29, 95-107.

HANDFORD, P. 1980. Heterozygosity at enzyme loci and morphological variation. Nature, 286, 261-262.

HEBERT, P. D. N. AND BEATON, M. 1989. Cellulose Acetate Gel Electrophoresis. Helena Laboratories, Beaumont, TX.

HOULE, D. 1989. Allozyme-associated heterosis in Drosophila melanogaster. Genetics, 123, 789-801.

KAT, P. W. 1982. The relationship between heterozygosity for enzyme loci and developmental homeostasis in peripheral populations of aquatic bivalves (Unionidae). Am. Nat., 119, 824-832.

LEAMY, L. 1982. Morphometric studies in inbred and hybrid house mice. II. Patterns in the variances. J. Hered., 73, 267-272.

LEAMY, L. 1984. Morphometric studies in inbred and hybrid house mice. V. Directional and fluctuating asymmetry. Am. Nat., 123, 579-593.

LEARY, R. F. AND ALLENDORF, F. w. 1989. Fluctuating asymmetry as in indication of stress: Implications for conservation biology. T.R.E.E., 4, 214-217.

LEARY, R. F., ALLENDORF, F. W. AND KNUDSON, R. L. 1983. Development stability and enzyme heterozygosity in rainbow trait. Nature, 301, 71-72.

LEARY, R. F., ALLENDORF, F. W. AND KNUDSON, R. L. 1984. Superior developmental stability of heterozygotes of enzyme loci in salmonid fishes. Am. Nat., 124, 540-551.

LEARY, R. F., ALLENDORF, F. W. AND KNUDSON, R. L. 1985. Inheritance of meristic variation and the evolution of developmental stability in rainbow trout. Evolution, 39, 308-314.

MCANDREW, B. J., WARD, R. D. AND BEARDMORE, J. A. 1982. Lack of relationship between morphological variance and enzyme heterozygosity in the plaice, Pleuronectes platessa. 
Heredity, 48, 117-125.

MITTON, J. B. 1978. Relationship between heterozygosity for enzyme loci and variation of morphological characters in natural populations. Nature, 273, 661-662.

MITTON, J. B., AND GRANT, M. C. 1980. Observations on the ecology and evolution of quaking aspen, Populus tremuloides, in the Colorado Front Range. Am. J. Bot., 67, 202-209.

MITTON, J. B., AND GRANT, M. C. 1984. Associations among protein heterozygosity, growth rate, and developmental homeostasis. Ann. Rev. Ecol. Syst., 15, 479-499.

NOSS, J. F., SCOTT, G. R., POTTER, R. H. AND DAHLBERG, A. A. 1983. Fluctuating dental asymmetry in molar dimensions and discrete morphological traits in Pima Indians. Am. J. Phys. Anthropol., 61, 437-449.

PALMER, A. A. AND STROBECK, C. 1986. Fluctuating asymmetry: Measurement, analysis, patterns. Ann. Rev. Ecol. Syst., 17, 391-421.

PARSONS, P. A. 1990. Fluctuating asymmetry and stress intensity. T.R.E.E., 5, 97-98.

PARSONS, P. A. 1992. Fluctuating asymmetry: a biological monitor of environmental and genetic stress. Heredity, 68, 361-364.

PETERS, R. H. 1983. The Ecological Implication of Body Size. Cambridge University Press, Cambridge.

PIERCE, B. A. AND MITTON, J. B. 1982. Allozyme heterozygosity and growth in tiger salamander, Ambystoma tigrinum. $J$. Hered., 73, 250-253.

QUATTRO, J. M. AND VRIJENHOEK, R. C. 1989. Fitness differences among remnant populations of the endangered Sonoran topminnow. Science, 245, 976-978.

SAS INSTITUTE INC. 1985. SAS User's Guide: Statistics, Version 5 Edition. SAS Institute, Cary, NC.

SINGH, S. M. AND ZOUROS, E. 1978. Genetic variation associated with growth rate in the American oyster (Crassostrea virginica). Evolution, 32, 342-353.
SOKAL, R. R. AND ROHLF, F. J. 1981. Biometry, 2nd Edn. Freeman, San Francisco, CA.

SOULÉ, M. E. 1979. Heterozygosity and developmental stability: Another look. Evolution, 33, 396-401.

SOULE, M. E. 1982. Allomeric variation. 1. The theory and some consequences. Am. Nat., 120, 751-764.

SOULÉ, M. E. AND BAKER, B. 1968. Phenetics of natural populations. IV. The population asymmetry parameter in the butterfly Coenonympha tullia. Heredity, 23, 611-614.

SOULÉ, M. E. AND COUZIN-ROUDY, J. 1982. Allomeric variation. 2. Developmental instability of extreme phenotypes. Am. Nat., 120, 765-786.

WERTH, C. R. 1985. Implementing an isozyme laboratory at a field station. Virginia Journal of Science, 36, 53-76.

WHITEHURST, P. H. AND PIERCE, B. A. 1991. The relationship between allozyme variation and life-history traits of the spotted chorus frog, Pseudacris clarkii. Copeia, 1991, 1032-1039.

WHITLOCK, M. C. 1992. None equilibrium population structure in forked fungus beetles: extinction, colonization, and the genetic variance among populations. Am. Nat., 139, 952-970.

VAN VALEN, L. 1962. A study of fluctuating asymmetry. Evolution, 16, 125-142.

VRIJENHOEK, R. C. AND LERMAN, S. 1982. Heterozygosity and developmental stability under sexual and asexual breeding systems. Evolution, 36, 768-776.

ZINK, R. M., SMITH, M. F. AND PATTON, J. L. 1985. Associations between heterozygosity and morphological variance. $J$. Hered., 76, 415-420.

ZOUROS, E. AND FOLTZ. D. w. 1987. The use of allelic isozyme variation for the study of heterosis. In: Rattazzi, M. C., Scandalios, J. G. and Whitt, G. S. (eds) Isozymes: Current Topics in Biological and Medical Research, vol. 13, A. R. Liss, New York, pp. 1-59. 